\title{
Dental concerns of children with down's syndrome - an overview
}

\begin{abstract}
Down's syndrome is a condition known to be associated with a chromosomal abnormality. This is usually in the form of three in place of a pair of chromosomes 21 , hence the name 'trisomy 21' the incidence of Down's syndrome in the population has been variably estimated between 1 and 4 per 1000 and which occurs in all races. These children are mentally retarded to some degree, they are generally smaller than average in height for their age, Midface dysplasia, flat broad bridge of the nose, "lop" ears, epicanthal folds with slanting almond-shaped eyes which was responsible for the term mongoloid. The majority of the children exhibit brachycephaly (broad, short head) and lack of supraorbital ridges and hypotelerism, Absence of frontal sinuses and absent or reduced maxillary sinuses, nasal septum or nasal conchl deviations are often observed which can produce a partially obstructed or narrow air passage and can contribute to the problem of mouth breathing, prone to infections especially upper respiratory tract infections. They have congenitally missing lateral incisors, the morphology of the teeth may also be affected. Teeth are smaller than normal, peg shaped and tend to be rounded or bulbous, roots of the incisors are short and most of the children are having tongue thrusting habit with lack of lip seal and high frenal attachment. They have a remarkable resistance to dental caries and at least half of them are caries free, preventive procedures along with chlorhexidine mouth wash may be beneficial and they suffer from a moderate to severe degree of periodontal disease. Down's syndrome children with congenital heart disease extractions and deep scaling should be done under antibiotic coverage and pulp treatment in primary teeth is contraindicated in patients with cardiac problems because of the risk of bacteremia whereas in permanent teeth it can be considered if an adequate apical seal can be obtained. Both orthodontic and prosthodontics appliances are usually contraindicated. Nitrous oxide analgesia or Tell show do in mildly apprehensive patients can be used, general anesthesia in severe resistance to dental treatment. This article discusses about etiological factors, clinical features and management aspects.
\end{abstract}

Keywords: children, caries, down's syndrome, periodontitis, saliva, oral health, management
Volume 6 Issue 3 - 2017

\author{
Nirmala SVSG,' Degala Saikrishna² \\ 'Department of Paedodontics \& Preventive Dentistry, India \\ ${ }^{2}$ Department of Oral and Maxillofacial Surgery, JSS Dental \\ College and Hospital, India
}

Correspondence: SVSG Nirmala, Department of Paedodontics \& Preventive Dentistry, Narayana Dental College \& Hospital, Nellore, Andhra Pradesh - 524003, India, Email nimskrishna2007@gmail.com

Received: October 29, 2016 | Published: March 07, 2017

\section{Introduction}

John Langdon Down was the first person to describe Down's syndrome in 1866 and he recognized the phenotypc expression of patients with circulation and coordination problems as having Down's syndrome. Further a century later, Jerome Lejeune hypothsized that nondysjunction during meiosis could lead to Trisomy of the 21st chrome. The incidence of T21 is one in 800 to 1,000 live births in the United States. ${ }^{1,2}$

There are three types of Down's syndrome, although it is generally thought that there is no clinical difference in the three geno types. ${ }^{3}$

i. Trisomy 21 (94\%): The extra 21 chromosome (three instead of the usual two) produces a complement of 47 chromosomes. Trisomy 21 may also be referred to as Trisomy G.

ii. Translocation (5\%): A segment of a 21 chromosome is found attached to other pairs of chromosomes (usually \#14, thus referred to as a 14/21 translocation). These individuals have the normal complement of 46 chromosomes.

iii. Mosaicism (1\%): Nondisjunction occurs at a later stage of cell division, therefore, some cells have the normal complement of 46 chromosomes and other cells 47 chromosomes (with an extra 21chromosome).

\section{General description}

Down's syndrome is a condition now known to be associated with a chromosomal abnormality. This is usually in the form of three in place of a pair of chromosomes 21 , hence the name 'trisomy 21 '. In a few cases the normal 46 chromosomes are present, but there is a translocation of an extra chromosome 21 to another site. The condition is more frequent in children born to older mothers, particularly those aged over 35years, but where the mother is young there may be an inherited translocation of one of the pair of chromosome 21. This then may become a third in the offspring, resulting in Down's syndrome. It has become an important to identify those families with inherited translocation in the field of counseling on family planning, and such a chromosome examination is now possible. ${ }^{3,4}$

The incidence of Down's syndrome in the population has been variably estimated between 1 and 4 per 1000. Some of this variability may be due to problems of diagnosis in the milder cases but more recent figures suggest that there is a real increase. It is a condition which occurs in all races. ${ }^{4}$

\section{Facial characteristics ${ }^{5,6}$ (Table I)}

Down's syndrome children are all mentally retarded to moderate to severe. They are delayed in their 'landmarks' of sitting up, standing, walking, talking and develop a slower pace than the normal so that 
they continue to lose ground. They are happy, affectionate children and may be mischievous though occasionally there may be aggressiveness in a particular case.

Table I Facial Characteristics

\begin{tabular}{|c|c|}
\hline Craniofacial & Midface Dysplasia \\
\hline Nose & $\begin{array}{l}\text {-Flat broad bridge, } 59-78 \% \\
\text {-Nasal septum or nasal conchal deviations } \\
\text {-narrow air passage }\end{array}$ \\
\hline Ear & $\begin{array}{l}\text {-"lop" ears, low-set ears } \\
\text { ears with a flat or absent helix 54\%. }\end{array}$ \\
\hline Eye Malformations & $\begin{array}{l}\text {-Epicanthal folds with slanting almond-shaped } \\
\text { eyes (narrow palpebral tissue slanting toward } \\
\text { the midline), which was responsible for the term } \\
\text { 'mongoloid' } 78 \% \text {. } \\
\text {-Strabismus (cross eyes) is reported in } 14-54 \% \\
\text {-Nystagmus (constant involuntary cyclical } \\
\text { movement of the eyeballs) and refractive errors }\end{array}$ \\
\hline Head & $\begin{array}{l}\text {-Brachycephaly (broad, short head) } \\
\text {-Lack of supraorbital ridges and } \\
\text {-hypotelerism (secondary to hypoplasia of the } \\
\text { central face) }\end{array}$ \\
\hline Sinuses & $\begin{array}{l}\text {-Absence of frontal sinuses } \\
\text {-Absent or reduced maxillary sinuses }\end{array}$ \\
\hline Mouth & $\begin{array}{l}\text {-open mouth, protruding tongue } \\
\text {-Fissured lips, narrow palate, irregular placed teeth }\end{array}$ \\
\hline Neck & -Broad and short \\
\hline Chest & $\begin{array}{l}\text {-Dorsolumbar khyphosis, flat nipples, pectus } \\
\text { excavatum, pectus carinatum, } \\
\text { flat nipples }\end{array}$ \\
\hline Abdomen & -Disastasis recti, umbilical hernia \\
\hline Hands & $\begin{array}{l}\text {-short broad, brachydactyly, single palmer } \\
\text { crease,clinodactly, fifth finger short, clinodactyly, } \\
\text { Single flexion crease on fifth finger }\end{array}$ \\
\hline Joints & -Hyperflexibility \\
\hline Genetalia & -Small penis and scrotum, cryptorchidism \\
\hline
\end{tabular}

The degree of mental retardation is very variable. Some are so severely affected as to be totally dependent and are in institutions. The majority of the children are in the grade of imbeciles and are trainable, but there is a group of higher grade of imbeciles and are trainable, but there is a group of higher grade who can be educated to a variable degree. The latter are likely to attend a special school, though rarely a normal one. It should be noted, however, that many of those classed as trainable only can now be taught to do much more than was hitherto supposed and with the right environment may come into educable group. ${ }^{4-7}$

The typical Down's syndrome child has many physical characteristics commonly present which distinguish him from the normal. He is generally smaller than average in height for his age, a gradual process which is less evident in the younger than the older child. ${ }^{8}$

He is plump and has a stooping, shuffling gait. His fingers are short flabby and his skin may be dry and rough. The skull is brachycephalic, in some even hyper-brachycephalic, and there is underdevelopment of the middle third of the face. This results in a flattening of the nose bridge which is present in three quarters of cases, and a small, short 'snub' nose. There are eye defects and in most cases the palpebral fissures slant downwards at the midline and an epicanthus is often present. Other eye abnormalities occurring the strabismus in more than half of the patients, nystagmus and lens opacities. Abnormalities in the form of the external ear are common. The hair may be fine and scanty and there is often a red flush in the cheeks. ${ }^{9}$
There is hypotonia of the lip muscles and the lower lip usually hangs loose, very often with persistent 'cracks' and the tongue protruding above it. The latter is often described as enlarge, but in most cases this appearance is due to lack of oral space with consequent protrusion. There is marked fissuring and the circumvallate papillae are enlarged. ${ }^{10}$

Some important medical abnormalities occur which have particular relevance. Congenital heart defects are present in approximately one third of these children and there may be cyanosis. There may be a disorder of the thyroid gland, with deficiency, and also hypopituitarism is postulated. Down's syndrome children are especially prone to infections and this result in bronchitis and other respiratory infection in particular. This is one of the main reasons why so few survive to any advanced age. There is also a higher than normal incidence of leukemia. ${ }^{11}$

\section{Medical conditions associated with down's syndrome9 (Table 2\&3)}

\section{Oral Condition}

Anomalies: As many as one third or most of these patients may have congenitally missing teeth, one or both maxillary lateral incisors are most frequent. The morphology of the teeth may also be affected. They are smaller than normal, peg shaped and tend to be rounded or bulbous. Fissural patterns may be varied and tend to be shallower. The incisors may be of a simpler form with under development of the lateral mamelons. Some retardation of eruption occurs, wrinkled occlusal surfaces of molars are believed to occur during tooth development. ${ }^{10-12}$ Children with Mongolism have an increased incidence of gastrointestinal tract anomalies, congenital heart disease, immunodeficiency, nutritional difficulties during infancy, seizure disorder, sleep apnea, visual impairment, audio logical dysfunction, weight gain toward adulthood and thyroid diorers. ${ }^{11}$ The immunologic problem is believed to be the major constituent in the high mortality rate seen in these patients. ${ }^{13-15}$

Table 2 Medical conditions associated with down's syndrome

\begin{tabular}{ll}
\hline Systems & Conditions \\
\hline Congenital & -Incidence of mitral valve prolapse (MVP) 40\%, \\
Cardiopathies & -Aortic regurgitation (AR) I4\%, ventricular septal defects \\
Nervous & $\begin{array}{l}\text { Delay in speech, distorted phonation due to imbalance of } \\
\text { neuromuscular system, Alzheimer } \\
\text { dementia }\end{array}$ \\
& $\begin{array}{l}\text {-Atlanto-axial instability is an abnormal } \\
\text { increase in mobility of the upper two cervical } \\
\text { vertebra (CI/C2) due to congenital ligamentous laxity. } \\
\text { (20\%), hyperflexibility of all joints. }\end{array}$ \\
& $\begin{array}{l}\text {-Higher incidence of upper respiratory tract } \\
\text { breathing and speech problems and along with nasal } \\
\text { septal deviations may complicate the use of general } \\
\text { anesthesia }\end{array}$ \\
Hematopoietic & $\begin{array}{l}\text {-Impaired immunologic response, Risk of lymphopenia, } \\
\text { eosinophilia, increased risk of leukemia, hepatitis B carrier } \\
\text { status if previously institutionalized } \\
\text {-Natural spontaneity, gentleness, patience and tolerance, } \\
\text { Behavior }\end{array}$ \\
\hline
\end{tabular}

Dental caries: Down's syndrome children have a remarkable resistance to dental caries and at least half of them are caries free. ${ }^{16}$ In those who do develop caries, the number of cavities is still far less than would be expected in a normal child. ${ }^{17}$ This may be in part be 
related to the simpler form of the teeth with few deep fissures. Living environment, dietary and hygiene habits, fewer erupted teeth due to high frequency of hypodontia and later eruption patterns have been proposed for the low prevalence of dental caries. ${ }^{18}$ Literature stated that based on analysis of electrolytes in oral secretions, related to the increased $\mathrm{pH}$ concentrations of sodium chloride and bicarbonate which together contribute to an increased buffering effect thereby reducing the opportunity for and duration of caries attack. ${ }^{19}$ The low prevalence has already been related to retarded eruption, smaller mesiodistal diameter with resultant diastema, poor periodontal status and early loss of alveolar bone, increased tooth mobility and exfoliation of tooth especially in the anterior part of the mandible..$^{20,2}$

Table 3 Other medical problems

\begin{tabular}{|c|c|}
\hline Systems & Conditions \\
\hline Congenital & -Incidence of mitral valve prolapse (MVP) $40 \%$ \\
\hline Cardiopathies & -Aortic regurgitation (AR) I4\%, ventricular septal defects \\
\hline Nervous & $\begin{array}{l}\text { Delay in speech, distorted phonation due to imbalance of } \\
\text { neuromuscular system, Alzheimer dementia }\end{array}$ \\
\hline Musculoskeletal & $\begin{array}{l}\text {-Atlanto-axial instability is an abnormal } \\
\text { increase in mobility of the upper two cervical } \\
\text { vertebra }(\mathrm{Cl} / \mathrm{C} 2) \text { due to congenital ligamentous laxity. } \\
(20 \%) \text {, hyperflexibility of all joints. }\end{array}$ \\
\hline Respiratory & $\begin{array}{l}\text {-Higher incidence of upper respiratory tract } \\
\text { infections (URTI) contributes to mouth breathing and } \\
\text { speech problems and along with nasal septal deviations } \\
\text { may complicate the use of general anesthesia }\end{array}$ \\
\hline Hematopoietic & $\begin{array}{l}\text {-Impaired immunologic response, Risk of lymphopenia, } \\
\text { eosinophilia, increased risk of leukemia, hepatitis B } \\
\text { carrier status if previously institutionalized }\end{array}$ \\
\hline Behavior & $\begin{array}{l}\text {-Natural spontaneity, gentleness, patience and tolerance, } \\
\text { anxiety and stubbornness in a few patients }\end{array}$ \\
\hline
\end{tabular}

Today, children with Down syndrome should be educated in proper oral hygiene, and receive the benefits of both systemic and topical fluoride. Occlusal sealants are also recommended. Decay in the primary dentition should be promptly treated. With the delayed emergence of the permanent teeth and the high number of missing teeth, it is critical to maintain the primary dentition as long as possible. $^{22}$

Periodontal condition: Almost all Down's syndrome children suffer from a moderate to severe degree of periodontal disease. Comparison with non Down's syndrome mental defectives in the same institutions shows that the Down's syndrome has a higher incidence of periodontal disease and that it is considerably more severe. It is most frequent in the mandibular incisor area and even at the age of 3years there may be tissue breakdown and early loss of the primary central incisors. ${ }^{20}$ Limited access to care, limited manual dexterity, and lowered efficacy of self home care are all the factors contribute in the increased levels of gingivitis in those who have mental disabilities compared to controls. ${ }^{21}$ Loss of their permanent successors before the mid-teens is more common.

There is separation of the attached gingival margin with pocket formation and progressive loss of supporting bone. This continues with age, and the involvement of the mandibular incisors followed by the maxillary incisors and the latter much of the rest of the dental arches. ${ }^{22}$ Radiographically, there is a lack of clarity of the lamina dura and the bone trabeculae appear shorter and thicker with consequently smaller marrow spaces. The roots of the incisors are short. Although the oral hygiene is often poor, it has little correlation with the degree of periodontal disease. ${ }^{23}$ Calculus is not and material alba were abundant in these children. Most of the Mongolism children were having tongue thrusting with lack of lip seal, high frenal attachment or in tight contact and traumatic occlusion could be contributing factors for periodontal diseases. ${ }^{24}$

\section{Malocclusion}

The small size of the maxilla with its lack of forward and downward development often results in an Angle's Class III malocclusion, occurring in one third or more of these children. ${ }^{25}$ The increased occurrence of class III malocclusion can be probably attributed to an underdeveloped maxilla, an enlarged and abnormally positioned tongue, or a relatively large and prognathic mandible. They exhibit asymmetric mocrognathic jaws with tooth malformations. ${ }^{26}$

There may be a posterior cross bite on one or both sides in addition to a reversed incisor overjet. Half of the patients have a tongue thrust, due in a few cases to an enlarged tongue, but in the majority of the children there is a lack of space for a tongue of apparently normal size. The prevalence of crossbite is approximately $90 \%$ and both thee genders being affected similarly. ${ }^{27}$

The majority of posterior crossbites are bilateral while anterior crossbites represented the second largest category and there were approximately equal percentages of unilateral right sided and unilateral left sided crossbites. This could be explained by the mandibular arch widths tended to exceed those of the maxilla. Crossbites likely to increase with increasing age in both sexes. ${ }^{28}$

Anterior open bite has been observed in $62 \%$ of boys and $48 \%$ in girls and posterior open bite was less in males comparatively females. The etiological factors associated with open bite is deficient maxillary growth accompanied by tongue thrust. This may result in an anterior open bite. There is often lack of lip seal and these factors may produce proclination of the mandibular incisors, accentuating the reversed incisor relationship..$^{29}$

Anterior crowding was present in $30 \%$ while posterior crowing in $39 \%$ this could be attributed to the tongue function, posture and size of the maxillary anterioposterior and vertical growth insufficiency. The tongue upon subjective evaluation, appeared to be either protruding on lying on the floor of the oral cavity.

Maxillary arch widths were consistently largerer than those of the mandible in normal children but in contrary, the mandibular arch widths were frequently equal to or larger than the maxillary arch widths. This could be due to the high incidence of unilateral cross bites and class III tendency. Male dimensions were 111 larger than female dimensions, the left side being more distant from the midline than the right side. ${ }^{30}$

\section{Dental treatment}

The degree of cooperation with dental treatment is largely dependent on the level of intelligence. The high grade or more intelligent Down's syndrome can be treated in the dental chair in a normal manner for conservative procedures. For lower grades the treatment must be tailored to the institutionalized case. There is no contraindication to local anesthesia in these children. ${ }^{41,42}$

\section{Intellectual disability/Behavioral concerns}

Children with Down's syndrome experience some degree of intellectual disability, typically in the mild to moderate range of cognitive disability, usually very easily accommodated within the "typical" dental office setting. Compliance issues should be dealt with in much the same way as for any other child presenting for dental treatment. The dental provider should demonstrate patience 
and respect for the individual when rendering care. All interventions should be explained to the child before beginning care. The child with Down syndrome may simply require a little and patience - especially during the first few visits. Sedation should only be used as a last resort, and only in extreme cases where care is vital and may not be performed in other way. ${ }^{44,45}$

Table 4 Medications are prescribed based on their medical condition

\begin{tabular}{lll}
\hline Symptom & Medication & Side effects \\
\hline Seizures & Anti convulsants (Dialantin sodium) & Gingival Hyperplasia \\
Hypertension & Calcium Channel Blockers & Xerostomia \\
\hline
\end{tabular}

Those children with congenital heart disease must have this taken into account when considering any plan of treatment. In such cases extractions and deep scaling should be done under antibiotic coverage and root canal therapy is contraindicated. This and the susceptibility to chest infection will influence any decision to use a general anesthesia either for extraction or for conservation. ${ }^{46}$

The periodontal condition constitutes the principal difficulty in attaining any degree of dental health. The disease is a progressive one and even in the high grade Down's syndrome, extraction of teeth may be unavoidable. Treatment of the gingival condition is in accordance with general principles but must be of a simple type. The possibility of the development of leukemia should be borne in mind. ${ }^{47}$

Both orthodontic and prosthodontics appliances are not very commonly used for several reasons. The gingival condition is poor, relatively large tongue and poor muscle tone make retention difficult, and temperamentally the cooperation is usually completely inadequate. Removable prothesis may be considered as a contraindication. Literature pertaining to Down's syndrome and rehabilitation with dental implants is lacking. The limited work to date has only shown partial success, but no conclusions can be drawn and further research is necessary to determine if patients with Mongolism are good candidates for implant therapy. The short roots are also disadvantageous for orthodontic tooth movement. ${ }^{38}$

Medications are prescribed based on their medical condition ${ }^{48}$ (Table 4).

\section{Behavior management ${ }^{49-51}$}

Many children with Mongolism can be successfully be treated in the dental office.

\section{Guidance}

a. Plan a pre-appointment (in person/phone) to discuss patient special needs prior to the first visit. Discuss this with the parent or care provider-they know the child best.

b. Schedule appointments early in the morning or best time of day for patient.

c. Talk with the parent or caregiver to determine the patient's level of intellectual and functional abilities and explain each procedure at a level the patient can understand.

d. Use short, clear instructions and speak directly to the patient.

e. Minimize distractions, such as sights and sounds, which may make it difficult for the patient to cooperate.

f. Start the oral examination slowly, using only fingers at first. If this is successful, begin using dental instruments.

g. Use the Tell-Show-Do approach when introducing new instruments or procedures. h. Reward cooperative behavior with positive verbal reinforcement.

Develop trust and consistency between the dental staff and the patient. Use the same staff, dental operatory, and appointment time each visit if appropriate. Frequency of sugar and bread based snacks should be limited.

Brush teeth twice daily with a soft toothbrush with fluoridated tooth paste and children less than 3years a thin "smear" of toothpaste where as children more than 5years "pea sized" amount of toothpaste is advisable.

They should be advised as visit the dentist regularly, it is recommended that every 3 months, but some people may need to go more often.

\section{Conclusion}

Dental care for the Down's syndrome children can be achieved in the general practitioner's office in most instances with minor adaptations. Although this population has some unique dental care needs, few patients require special facilities in order to receive dental treatment. Adequate dental health care for persons with developmental disabilities is a major unmet health need. A thorough knowledge of the unusual dental implications of this syndrome and an innovative problem solving approach to treatment planning and preventive procedures will do much to alleviate the dental effects of these children.

\section{Acknowledgments}

None.

\section{Conflicts of interest}

Author declares there are no conflicts of interest.

\section{Funding}

None.

\section{References}

1. Smith GF, Berg JM. Down's anomaly (2nd edn), Scotland. p. 100-149.

2. Mattei JF, Mattei MG, Ayme S, et al. Origin of the extra chromosome in trisomy 21. Hum genet . 1979;46(1):107-110.

3. CM Clarke, JH Edwards. Trisomy-21/normal mosaicism in an intelligent child with some mongoloid features. Lancet. 1961;277(7185):1028-1030.

4. Frostad WA, Cleall JF, Melosky LC. Craniofacial complex in the trisomy 21 syndrome (Down's syndrome). Arch Oral Biol. 1971;16(7): $707-722$.

5. Oster J. Mongolism in a clinic-pathological investigation comprising 526 Mongolis living on Seeland and neighbouring islands in Denmark. Copenhagen Danish Science Press Ltd, Denmark. 1953.

6. Macho V, Coelho A, Areias C, et al. Craniofacial features and specific oral characteristics of Down syndrome children. Oral Health Dent Manag. 2014;13(2):408-411.

7. Levinson A, Friedman A, Stamps F. Variability of mongolism. Pediatrics. 1955;16(1):43-54.

8. Gosman SD. Facial development in Mongolism. Am J Orthod. 1951;37(5):332-349.

9. Burwood RJ, Gordon IR, Taft RD. The skull in Mongolism. Clin Radiol. $1973 ; 24(4): 475-480$. 
10. Spitzer R, Rabinowitch JY, Wybar KC. A study of the Abnormalities of the Skull, Teeth and Lensesin mongolism. Can Med Assoc J. 1961;84(11):567-572

11. Clemens E Benda. Mongolism and cretinism. London, Heinemann. $1949 ; 20-24$.

12. Shore S, Lightfoot T, Ansell P. Oral disease in children with Down syndrome: Causes and prevention. Community Pract. 2010; 83(2):18-21.

13. Tannenbaum KA. The oral aspects of mongolism. J Pub Health Dent 1975;35(2):95-108.

14. Johnson NP, Watson AO, Massier M. Tooth ring analysis in mongolism. Aust Dent J . 1965;10(4):282-286.

15. CM Clarke, JH Edwards. Trisomy-21/normal mosaicism in an intelligent child with some mongoloid features. Lancet. 1961;277(7185):1028-1030.

16. RH Brown, WM Cunnigham. Some dental manifestations of mongolism Oral surgery, Oral medicine, Oral pathology. 1961;14(6): 664-676.

17. Creighton WE, Wells HB. Dental caries experience in institutionalized mongoloid and nonmongoloid children in North Carolina and Oregon, $J$ Dent Res. 1966;45(1): 66-75.

18. Vigild M. Dental caries experience among children with Down's syndrome. J Ment Defic Res. 1986;30(pt 3):271-276.

19. Johnson NP, Young MA, Gallios JA. Dental caries experience in mongoloid children. J Dent Res. 1960;27:292-294.

20. Creighton WE, Bradely Wells H. Dental caries in mongoloid children. $J$ Dent Res. 1966;45(1):66-75.

21. Barnett ML, Press KP, Friedman D, et al. The prevalence of periodontitis and dental caries in a Down's syndrome population. $J$ Periodontol. 1986;57(5):288-293.

22. Areias CM, Sampaio Maia B, Guimaraes 11, et al. Caries in Portuguese children with Down syndrome. Clinics (Sao Paulo) 2011;66(7):1183-1186

23. Reuland Bosma W, Liem RS, Jansen HW, et al. Morphological aspects of the gingiva in children with Down's syndrome during experimental gingivitis. J Clin Periodontol. 1988;15(5):293-302.

24. Cohen MM, Winer RA, Schwartz S, et al. Oral aspects of mongolism. I. Periodontal disease in mongolism. Oral Surg Oral Med Oral Pathol. 1961;14:92-107.

25. Sznajder N, Carraro JJ, Otero E, et al. Clinical periodontal findings in trisomy 21 (mongolism). J Periodontal Res. 1968;3(1):1- 5.

26. Morgan J. Why is periodontal disease more prevalent and more severe in people with Down syndrome? Spec Care Dentist. 2007;27(5):196-201.

27. Sassouni V, Forrest E. Dentofacial pathology related to malocclusions. Orthodontics in dental practice. St Louis: Mosby. 1971. p169-p197.

28. Reuland Bosma W, Reijden WA, Winkelhoff AJ. Absence of a specific subgingival microflora in adults with Down's syndrome. J Clin Periondontol. 2001;28(11):1004-1119.

29. Cohen MM. Occlusal Disharmonies in Mongolism (Down's Syndrome) Am J Orthod. 1971;60(1):88.

30. Robertsson S, Mohlin B. The congenitally missing upper lateral incisor. A retrospective study of orthodontic space closure versus restorative treatment. Eur J Orthod. 2000;22(6):697-710.
31. Roche AF, Seward FS, Sunderland S. Growth changes in the mongoloid head. Acta Paediatr Scand. 1961;50:133-140.

32. Rozner L. Down's Syndrome and tongue size. Med J Aust. 1984;140(3):196-197.

33. Moura CP, Andrade D, Cunha LM, et al. Down syndrome: Otolaryngological effects of rapid maxillary expansion. J Laryngol Otol 2008;122(12):1318-1324.

34. Frostad WA, Cleall JF, Melosky LC. Craniofacial complex in the trisomy 21 syndrome (Down's syndrome). Arch Oral Biol. 1971;16(7):707-722.

35. Pilcher ES. Dental care for the patient with Down syndrome. Down Syndrome Research and Practice. 1998;5(3): 111-116.

36. Skrinjaric T, Glavina D, Jukić J. Palatal and dental arch morphology in Down syndrome. Coll Antropol. 2004;28(2):841-847.

37. Brown RH. Dental treatment of the mongoloid child. $J$ Dent Child (Chic). 1965;32:73-81.

38. Musich DR. Orthodontic intervention and patients with Down syndrome. Angle Orthod . 2006;76(4):734-735.

39. Ferrario VF, Dellavia C, Serrao G, et al. Soft tissue facial angles in Down's syndrome subjects: a three-dimensional non-invasive study. Eur J Orthod. 2005;27(4):355-362.

40. Townsend G. A correlative analysis of dental crown dimensions in individuals with Down syndrome. Hum Biol . 1987;59(3):537-548.

41. RH Brown, WM Cunnigham. Some dental manifestations of mongolism. Oral surg oral med oral pathol . 1961;14(6):664-676.

42. Pilcher ES . Dental care for the patient with Down syndrome. Down Syndrome Research Practice. 1998;5(3):111-116.

43. L Nadel. Down's syndrome: a genetic disorder in biobehavioral perspective. Genes Brain Behav. 2003;2(3):156-166.

44. Raposa KA. Behavioral management for patients with intellectual and developmental disorders. Dent Clin North Am . 2009;53(2):359-373.

45. Scully C, Langdon J, Evans J. Marathon of eponyms: 4 Down syndrome. Oral Dis. 2009;15(6):434-436.

46. Butler MG, Hayes BG, Hathway MM, et al. Specific genetic diseases at risk for sedation/anesthesia complications. Anesth Analg. 2000;91(14):837-855.

47. Pueschel SM. Clinical aspects of Down syndrome from infancy to adulthood. Am J Med Genet Suppl. 1990;7: 52-56.

48. Lustig JP, Yanko R, Zilberman U. Use of dental implants in patients with Down syndrome: a case report. Spec Care Dentist . 2002;22(5):201-204.

49. Fenton SJ, Perlman S, Turner H (ed.). Oral Health for People with Special Needs: Guidelines for Comprehensive Care. River Edge, NJ: Exceptional Parent, Psy-Ed Corp. 2003.

50. Roizen NJ. Down syndrome. In Batshaw ML, Pellegrino L, Roizen NJ (ed.), Children with Disabilities (6th edn), Baltimore, MD: Paul H. Brookes Publishing Co. 2007.

51. Weddell JA, Sanders BJ, Jones JE. Dental problems of children with disabilities. In McDonald RE, Avery DR, Dean JA. Dentistry for the Child and Adolescent (9th edn), St Louis, MO: Mosby. 2015. p 460-486. 